\title{
NEW TECHNOLOGIES: SENSOR AND LENS UHD-8K FULL FRAME 24X36MM WITH AGNOSTIC ASPECT RATIO
}

\section{Chair: Celso Araujo, Diretor de Cinema SET, Diretor LINK Multisserviços Eletroeletrônicos}

A slow and silent trend has been observed with the launch since 2014 of Lenses for the size of the image area with Aspect Ratio FULL FRAME (36x24mm), although there is still no camera with such specification, just a few of photography. A wide variety of Full Frame film lenses are available today as ZEISS, FUJINON, SCHNEIDER, SIGMA, LEICA, CANON, SONY, IB / E, SAMYANG, TOKINA and others. The optical industry for the first time anticipated that of cameras. The FULL FRAME format offers greater and better cosmetic and depth-of-field benefits, as well as a magnification of about 1.5 times compared to traditional S35mm film capture. This larger sensor size is actually more advantageous since pixels with larger dimensions admit a higher amount in the light capture and thus resulting in greater sensitivity. The Panel will introduce the new technologies of these newly launched Lenses and discuss the trends of sensors and film cameras, including the industry's latest announcement regarding Full Frame Cinema Camera.

\section{- MARKET TRENDS}

Speaker: Mario Jannini - Technical Director - ARRI Brasil

To keep the image quality, it means, to keep or improve the High Dynamic Range (HDR), texture, skin tones, low noise, the sensor must increase its size compared to the Super 35, and it can be Full Frame or even bigger, as the new ARRI PL-X Mount from ALEXA 65.

- 8K OPTICAL DEVELOPMENT, MAIN CHALLENGES AND APPROACH TO A NEW LEVEL OF REQUIREMENTS

Speaker: Gordon Tubbs - Vice President at FUJIFILM North America Corporation, Optical Device Division

- ACQUISITION TECHNOLOGIES: SENSORS FOR BEYOND DEFINITION APPLICATIONS 


\section{Speaker: ERICK SOARES Marketing | Professional Solutions Brazil | Sony Brasil Ltda.}

An overview for sensors technology evolution and development including possible applications, covering different technologies such as $1 / 3$ " up to Super $35 \mathrm{~mm}$. Due to increasing demand for Beyond Definition applications, including 4K, 8K, HFR and HDR, new technologies are being developed for some specific new applications or in order to improve performance, where some examples will be covered, including Full Frame sensors and its benefits.

- LENS TECHNOLOGY IN A FULL FRAME PLUS WORLD Speaker: ERIC J JOHNSTON - ZGC / COOKE OPTICS

- THE BENEFITS AND CHALLENGES IN PRODUCTIONS WITH NEW TECHNOLOGIES AND STANDARDS - 4K, 8K, HDR, HFR, FULLFRAME

Speaker: Cristiano Barbieri - Head of Sales - ITCG - Imaging Technologies \& Communications - CANON Group of Brasil

We will present the evolution and embedded technologies in Lenses and Cameras to meet the new demands for higher resolutions ( $4 \mathrm{~K} \& 8 \mathrm{~K}$ ), and the technical / operational benefits of new technologies that goes beyond resolution to produce even more compelling contents, from the aquisition to monitoring, such as High Dinamic Range, Color Volume e High Frame Rate.

- ZEISS LENS SOLUTIONS FOR 8K AND BEYOND - READY FOR THE FUTURE

\section{Speaker: Snehal Patel - ZEISS Cine Sales Manager for the Americas}

ZEISS has been providing the cinema communities around the world with cinema lenses for over 80 years. R\&D is very important for our company culture and ZEISS is always developing forwardthinking technologies to aid customers in their creative process. In fact, ZEISS already has Full Frame lens solution in the form of Cine Primes and Cine Zooms. During this workshop, Snehal Patel, Cine Sales Manager for the Americas, will discuss how the Compact Prime and Cinema Zoom lenses from ZEISS are used every day with large sensor cameras like the RED Weapon VV, Panavision DXL, ARRI Alexa 65 and other cameras. 

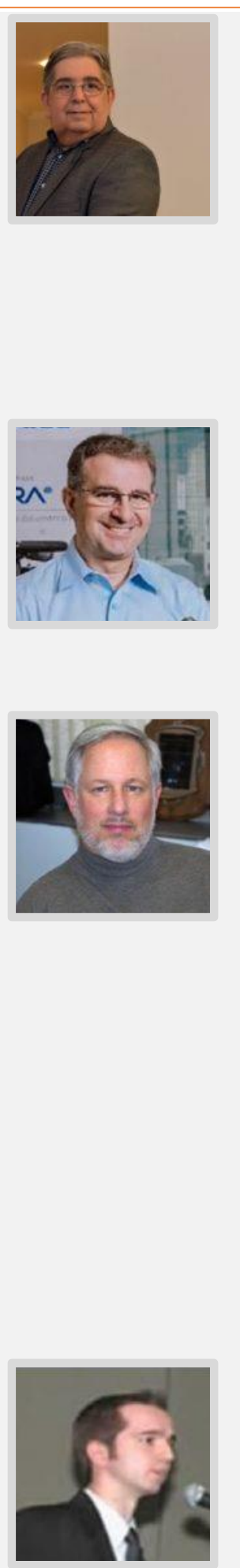

\section{Celso Araujo, Diretor de Cinema SET, Diretor LINK Multisserviços Eletroeletrônicos}

He joined TV Globo in 1973, where he worked for 40 years at the Central Globo de Engenharia, in Rio de Janeiro. He spent more than 12 years in maintenance, during which he had the opportunity for development in various sectors of the television maintenance, such as cameras, lenses, video, audio, switchers, routers, and even the management of systems and crews for production operations in sporting events, shows, World Cup and Olympics. Since 2013 acting as Entrepreneur, Business Consultant in the area of TV Technology and providing Seminars and Workshops with SET at its regional events, to the IAV (Audiovisual and Video Institute of São Paulo).

\section{Mario Jannini - Technical Director - ARRI Brasil}

Graduated in electrical engineering, he has been working in the video and digital cinema market for more than 22 years, mainly in the area of image capture. After 4 and a half years at ARRI Inc. (USA), took the recent ARRI affiliate in Brazil as technical director of services and supports in sales and maintenance of lighting, cameras, lenses and accessories from ARRI cameras.

\section{Gordon Tubbs - Vice President at FUJIFILM North America Corporation, Optical Device Division}

Mr. Tubbs is the Vice President for Broadcast and Cinema Lens Products within the Optical Devices Division of Fujifilm North America Corporation, based in Valhalla, New York USA. Fujifilm North America Corporation is responsible for the Sales and Support of all Fujinon branded lenses and accessories in North, Central and South America. He joined Fujinon / Fujifilm in 2010 as Director of Sales, previously he had spent the majority of his thirty six year career with the broadcast division of Canon USA Inc. as well as with Ikegami and Angenieux in the United States. With the recent introduction of Fujinon's Ultra HD 2/3" $4 \mathrm{~K}$ lenses as well a complete line of $4 \mathrm{~K}$ Digital Cinematography lenses, these new optical, mechanical and digital products have opened up a third major technological era for him after having already worked in Standard Definition and High Definition television throughout his career. In addition, he has been involved in the preparation for and onsite support of many major television events requiring the latest optical technologies such as the Olympics, Super Bowl, World Series, US Open Tennis and other major broadcasts.

\section{Erick Soares - Marketing | Professional Solutions Brazil | Sony Brasil Ltda.}

Sales Support Specialist, acting for more than 15 years for Sony as specialist and evangelist for new technologies, workflows and products for the Broadcast market. Graduated by F.E.I. (Industrial Engineering University Center - S.B.C /SP) and Post-Graduated by F.I.A. Business School (USP), supported new products development and provided market feedback, coordinated strategic projects implementation, acting as interface between local Brazilian customers and engineering team from Japan, as well as attended key local and international events. 


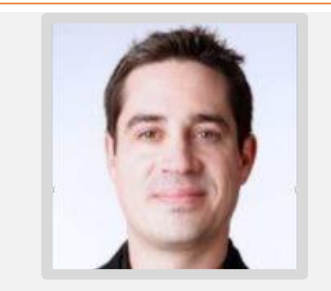

\section{Eric J Johnston - ZGC / COOKE OPTICS}

With 20 years' experience representing the biggest names in professional cinema equipment, Eric will now be concentrating on sales for the Americas region.He joins ZGC after seven years with the Vitec Group, originally as Product Specialist for the OConnor accessories brand and subsequently as Strategic Account Manager for Digital Cinema and Rental Houses across seven Vitec Videocom brands He is a sales professional who is intensely customer focused and brings with him a passion for the motion picture industry and its art. Eric animated his 1st short film at the age of eight and is an Associate Member of the American Society of Cinematographers.

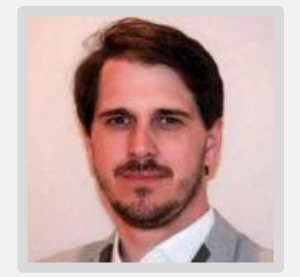

Cristiano Barbieri - Head of Sales - ITCG - Imaging Technologies \& Communications - Grupo CANON do Brasil

Cristiano is graduated in Engineering of Telecomunications by FEl (Faculdade de Engenharia Industrial), with MBA in Project Management by FGV. With more than 15 years of experience in the Broadcast \& Media market he worked at Harris Broadcast and Grass Valley as Sales Manager, and currently is Head of Sales at Canon do Brasil developing business in the Broadcast, Cinema and Professional Video segments.

Snehal Patel - ZEISS Cine Sales Manager for the Americas

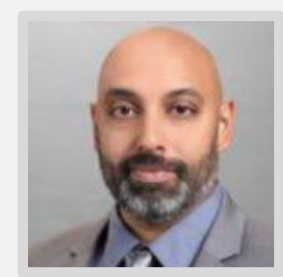

